\title{
Natural Sorbents in Agriculture
}

\author{
Georgy A. Yarmots \\ Department of Feeding and Breeding of Farm Animals \\ FSBEI HE Northern Trans-Ural SAU \\ Tyumen, Russia \\ yarmozga@gausz.ru
}

\author{
Lyudmila P. Yarmots \\ Department of Feeding and Breeding of Farm Animals \\ FSBEI HE Northern Trans-Ural SAU \\ Tyumen, Russia \\ yarmotslp@gausz.ru
}

\begin{abstract}
The main characteristic of sorbents is their polarity. The function of additives is based on their ability to connect and remove harmful substances from the animal stomach. The paper describes the influence of natural sorbents zeolite and bentonite - on nutrient digestibility, milk productivity and its chemical composition. The introduction of $200 \mathrm{~g}$ of zeolite into the diet of cows allowed increasing the digestibility coefficients of crude protein by $3.17 \%$, crude fiber by $5.07 \%$, and hence producing $4 \%$ of milk per $256.34 \mathrm{~kg}$ or by $10.82 \%$ more. The use of bentonite increases the dry matter digestibility by $1.68 \%$, crude fat - by 1.52 , crude fiber - by $6.48 \%$, which in turn increased milk production by over $655.63 \mathrm{~kg}$.
\end{abstract}

Keywords - sorbents, bentonite, zeolite, milk productivity, chemical composition of milk, digestibility coefficient

\section{INTRODUCTION}

In order to increase the livestock production there is a need to improve feed supply, to find new feed additives and biologically active agents alongside with the creation of new highly productive animal breeds.

The maximum implementation of hereditary potential of farm animals' efficiency through the intensification of exchange processes opens additional opportunities for yield enhancement without additional feed costs. Therefore, alongside with such factors as safety and quality improvement of feeds and diets, optimization of animal management conditions, new feed additives - metabolism regulators are widely used in animal feeding. The effect of such additives is caused by their regulating influence on the intensity of digestion and use of feed nutrients thus creating a possibility of purposeful management of these processes.

The in-depth study on the use of mineral feeding in production conducted in recent years is based on natural factors. Wild animals prefer faolites - minerals of the zeolite group.

Considering the above, the use of natural minerals sorbents, namely kudyurites as feed additives is quite promising.

They include varieties of the earth's crust (zeolite, bentonite, quartzite, clay, shale and other types of minerals) used by animals as sources of calcium and microelements characterized by various mineral composition and sorbing, buffering and ion-exchange properties [1, 2, 3]. This will provide for more efficient use of natural resources from traditional feeds and consistent reduction of feed costs for milk production.

According to some authors, the use of natural minerals in feeding of farm animals positively influences their digestion and increases the feed availability due to highly digestible forms of calcium, potassium, microelements of cobalt, copper, zinc and other chemicals that are extremely necessary for the organism of farm animals.

There are about 40 types of natural zeolites (NZ). The most popular include clinoptilolite, mordenite, heulandite, erionite, chabasite, phillipsite. They contain over 40 mineral elements. Among them, the oxides of silicon, aluminum, iron, calcium, magnesium, sodium, potassium, and phosphorus have the largest specific weight. The microelements so important for animal feeding include iron, copper, zinc, manganese, cobalt, selenium, and molybdenum.

The NZ influence on the organism depends both on their physical, chemical and mechanical properties, and on animal feeding and management conditions, as well as on environmental conditions. Numerous experiments and field tests proved that the zeolite content in a rock for ruminants shall make at least $65 \%(70 \%$ and above is even better), for pigs and birds - at least 55\%. Tuff feeding with zeolite content below the minimum level is often not positive, though not too negative for metabolism and productivity.

The positive effect of zeolites on animal organisms is based on their sorption and ion-exchange properties, as well as enrichment of diets with macro- and microelements.

According to some studies [1] conducted for birds, the chemical changes of minerals include ion-exchange properties. Comparison of results of chemical analyses of zeolite at the input and output clearly indicates the ion-exchange reactions. At the output the stone mineral is enriched with phosphorus, potassium and is characterized by calcium deficit.

Phosphorus had the highest exchange coefficient, i.e. in the zeolite tuff it was almost 4 times higher at the output than at the input. Besides, the potassium content increased 2.6 times and sodium - by $33 \%$. The zeolite tuff removes other elements, such as magnesium, silicon, manganese, titanium, iron and calcium. High level of calcium exchange was also observed. $46.8 \%$ of the element was withdrawn from the rock. For iron, titanium and manganese this indicator was slightly lower $(22.7 ; 21.7 ; 18.7 \%$ respectively). Most likely, the zeolite 
serves the regulator of mineral exchange in a bird organism during digestion due to deficit of some and surplus of other elements.

The chromatographic study showed that gaseous products of metabolism - carbon dioxide, hydrogen, methane, carbon monoxide and ammonia are actively occluded by all zeolite fractions.

Bentonites represent a variety of bleaching clays formed as a result of chemical changes of volcanic rocks - tuff and ashes. They are generally composed of a mineral group montmorillonite, where various elements, mostly aluminum and calcium act as cations in a montmorillonite molecule [4].

Bentonites are formed from such elements necessary for animal organism as calcium, sulfur, magnesium, iron, copper, zinc, manganese and others, i.e. those elements, which are currently additionally introduced into the diet of animals.

One of the most important natural features of bentonites is their dispersive capacity, which is dependent on type and quantity of exchange cations of clay: the more bentonite particles of exchange cations of alkaline metals, usually sodium, in a diffusion layer, the higher its dispersion. Bentonites are characterized by high water absorption or moisture retention capacity in comparison with other types of clays, where alkaline bentonites have higher water absorption than alkaline-earth bentonites.

High ion-exchange capacity, reversible hydration, gas absorptivity, mainly ammonia and sulfur dioxide are typical for bentonite clays. Besides, clay has high bonding properties, adsorption and catalytic activity. Compared to other minerals, bentonite has higher exchange capacity. Through the exchange of metal cations, it regulates calcium, iron and other elements in the organism. At the same time, there are no poisonous elements such as arsenic, bismuth, mercury, antimony, etc. in bentonites $[4,5]$.

Bentonites easily connect organic bases and their salts thus forming clay-organic complexes - bentons. The bonding properties of bentonites are caused by the developed surface on the boundary of solid and liquid phases and the considerable surface energy margin. The bonding between clay particles in aqueous media is amplified with the removal of water and their rapprochement. The complete removal of water (artificial drying) results in quite strong bonding, which ensures strong coalescence and adhesion of particles both among themselves and with particles of the materials which they contact. At the same time, due to their scale structure the clay particles are oriented across planes thus forming relatively strong bonds.

Bentonite clays attract water molecules by hydrogen bond forces and hold them thus forming a strong monomolecular layer with the maximum energy effect. Hence, the water of the formed layer mainly characterizes the surface properties of a mineral.

In nature bentonite clays quite often form the large-scale deposits being commercially useful. One of the largest is the Zyrianskoye field of the Kurgan region, which economic reserves account for 30 million tons [6].
Petrukhin I.V. in his study on the influence of bentonite clays on the organism of milk cows noted that bentonites are characterized by hydrophilic properties. Such qualities of clay as the monoexchange ability, surface activity, and adsorption positively influence the feed nutrient intake. Z. Weinberg added another characteristic to these properties: bentonite reduces tension on fat-water phase boundary, and similar to bile acids, improves the absorption of fatty acids and fatsoluble substances.

F.R. Arakelyan expressed an opinion concerning metabolism of bentonite silicon in the animal organism. Though many literature sources refer to the fact that silicon oxide is inert bond for animals, but the exchange of this element in the animal organism is similar to phosphorus metabolism. He supposed that silicon oxides play an essential role in all metabolic processes of an organism, in particular, lipid metabolism

Due to adsorption capacity of bentonite the unwanted liquid, harmful gases and endotoxins are removed from the digestive tract of animals thus improving feed digestion and preventing diarrhea. It is supposed that the functioning of harmful bacteria is suppressed in a digestive tract due to change of hydrogen ions concentration caused by ionexchange effect of bentonite.

Bentonite clays are positive for diet density, which is explained by the presence of unidentified growth factors [7].

The implementation of ion-exchange properties of a sorbent ensures the introduction of highly digestible forms into the digestive tract from among those macro- and microelements contained in clay, which can actively participate in metabolism since alongside with the increase of digestibility and availability of diet nutrients the organism environment is enriched and balanced with mineral substances [8].

The spectral analyses showed that the concentration of crude ash, zinc and manganese in pig hair fed with bentonite at a dose of $1-2 \%$ of the feed dry matter was higher than in case with control animals

It is found that bentonite fosters metabolism in the organism, ensures better digestion of nutrients, increases productivity by $5-8 \%$, natural resistance and contributes to high quality of final products [9].

Large mineral reserves cause the need to provide scientific justifications to their use in feeding of farm animals as a rich source of the mineral feed.

Thus, the Zyrian bentonite contains (\%): calcium - 1.89, phosphorus -0.03 , magnesium -1.25 , sodium -0.47 , potassium -0.5 , iron -0.85 , manganese -0.014 , copper 0.08 , zinc -0.04 and ash -85.2 .

$\mathrm{Mg}$ and $\mathrm{Ca}$ prevail in the Trans-Ural field thus referring bentonites of the Zyrian field to the category of alkaline-earth minerals. The prevalence of magnesium in the exchange complex is a distinctive feature of the Trans-Ural bentonite field compared to others. Besides, the Zyrian bentonite is rich in aluminum and iron oxides. 
The estimated kudyurite resources and reserves of Russia make 5-6 billion tons. This problem is also relevant for Siberia since its territory is known for huge deposits of mineral raw materials of high-siliceous complexes suitable for use in agricultural industry.

Special attention is paid to mineral substances in the system of adequate nutrition of dairy cattle. Various mineral additives of both industrial production, and natural sources of mineral substances (zeolites, bentonites, etc.) are used to balance the diet in terms of macro- and microelement concentration.

\section{PURPOSE OF THE STUDY}

The main the purpose of the study was to define the efficiency of natural mineral additives (zeolite, bentonite) in diets of black spotted cows and to reveal their influence on milk productivity, consumption and digestibility of feed nutrients, exchange of energy, nitrogen, calcium and phosphorus, as well as hematologic indicators.

\section{MATERIALS AND METHODS}

The research work was carried out for black spotted cows at the educational and experimental farm of the Northern Trans-Ural State Agricultural University. Ten groups of animal analogs of 10 heads were formed for the study taking into account their age, body weight, productivity and physiological state. The need for feed and nutrients was estimated in compliance with standards recommended by the Russian Academy of Agricultural Sciences. In the first experimental study the cows of the control group received a diet accepted in a given farm. The cows of the test group received additional $200 \mathrm{~g}$ of zeolite. In the second experiment the cows of the test group additionally received $200 \mathrm{~g}$ of bentonite.

The tests followed the physiological research to study metabolism, milk productivity and chemical composition of milk.

\section{FINDINGS}

Use of zeolites in diets of cows.

Twenty down-calving cows split into two groups of 10 heads each were selected to define the efficiency of zeolite. The level and type of down-calving cow feeding corresponded to the one accepted in a given farm. The animals of the test group additionally received $200 \mathrm{~g}$ of zeolite. After calving the cows received a diet implied by the study scheme.

The digestibility of nutrients was studied throught the physiological experiment carious out alongside with research and production test on 6 cow analogs. Daily accounting of feed eaten by animals and the analysis of their chemical composition allowed establishing the amount of nutrients consumed during digestion trial.

The cows of the test group consumed more fry matter, organic substances, crude protein, crude fat and nitrogen-free extractive substances than the animals of the control group.

The total nutrients and energy cannot indicate its real value since a considerable amount of nutrients of a diet is not absorbed into the digestive tract but is removed with faeces taking away some energy.

More objective understanding of feed nutritiousness is ensured by its digestible nutrients.

V.S. Zoteev, V.N. Vinogradova, et al. [10] found that the zeolite tuff exerts positive impact on digestibility and use of feed nutrients thus increase the productivity of a diet.

Zeolites stimulate metabolic processes, improve digestibility of nutrients and use of feed nitrogen [11].

According to G.A. Romanov, L.Ya. Makarenko [12], the improvement of protein digestibility is caused by the ability of this mineral to absorb ammonia molecules and to emit them while moving along the digestive tract thus increasing the level of its use.

The analysis of physiological experiments showed that coefficients of nutrient digestibility of the studied diets of test animals were relatively high (Figure 1).

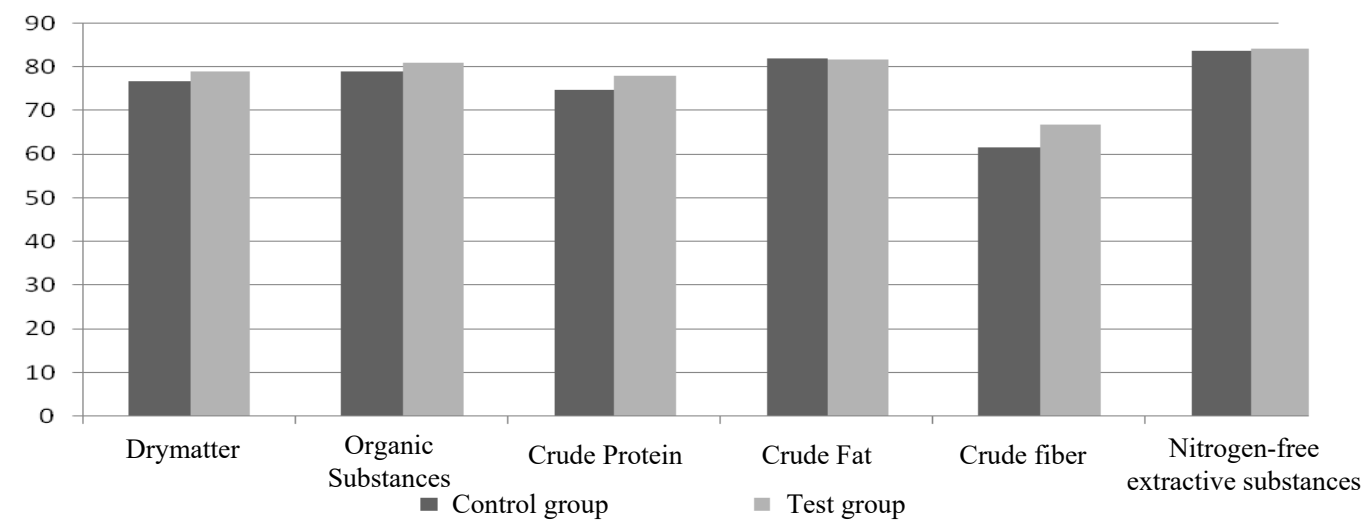

Fig. 1. Coefficients of nutrient digestibility, $\%$ 
The animals of the test group better digested crude protein and crude fiber. Thus, the coefficient of crude protein digestibility of cows of the test group was higher by $3.17 \%$ $(\mathrm{P}<0.05)$ and crude fiber - by $5.07 \%$ than in the control group.

Crude fat and nitrogen-free extractive substances were digested by animals without significant differences though there was a tendency towards the increase in their digestibility by the test group.

Thus, the use of zeolite in diets of lactation cows ensures better digestion of feed nutrients and normal metabolic processes in their organism.

The animals of the test group consumed $5.24 \mathrm{~mJ}$ more gross energy than their analogs in the control group.

The animals of the test group emitted less energy with faeces - by $4.30 \mathrm{~mJ}$ in comparison with the control group, which affected the amount of digestible energy. The digestible energy of cows the test group made $9.54 \mathrm{~mJ}$, or $3.86 \%$ higher than that of the control group.

The main feature of cattle energy exchange is that about $70 \%$ of energy needs of an organism is covered by volatile fatty acids (VFA) produced by rumen microorganisms.

The biochemical study of ruminal chyme showed that the introduction zeolite tuff in cow feed intensified the fermentation processes in a rumen. This is mainly confirmed by a higher level of VFA (by $21.2 \%$ ). The quantity of microflora of the test cows increased, which not only intensified the fermentation processes, but also biosynthetic ones.

Thus, the introduction of zeolite into the diet of cows positively influences the efficiency of energy exchange.

The influence of zeolites on milk productivity and composition was studied over 100 days of lactation. The experience and research findings show that a diet, its components and feeding adequacy have a great impact on milk synthesis and its composition.

TABLE I. MILK PRODUCTIVITY OF COWS OVER THE FIRST 100 DAYS OF LACTATION $(\mathrm{X} \pm \mathrm{SX})$

\begin{tabular}{|c|c|c|}
\hline \multirow{2}{*}{ Indicator } & \multicolumn{2}{|c|}{ Group } \\
\cline { 2 - 3 } & control & test \\
\hline $\begin{array}{c}\text { Milk yield over 100 days of } \\
\text { lactation: }\end{array}$ & & \\
\hline $4 \%$ fat, kg & $2370.09 \pm 62.18$ & $2626.43 \pm 56.05$ \\
\hline Day-night milk yield: & & \\
\hline $4 \%$ fat, kg & $23.70 \pm 0.62$ & $26.26 \pm 2.56$ \\
\hline Fat mass fraction, $\%$ & $3.98 \pm 0.22$ & $4.05 \pm 0.10$ \\
\hline Milk fat, kg & $94.80 \pm 2.59$ & $105.06 \pm 1.24 *$ \\
\hline Protein mass fraction, $\%$ & $3.18 \pm 0.04$ & $3.17 \pm 0.01$ \\
\hline Milk protein, kg & $75.75 \pm 2.98$ & $82.23 \pm 2.52$ \\
\hline
\end{tabular}

The milk yield is the main criterion justifying the efficiency of any studied additive.

The difference in milk yield of the control and test groups was noted in the first days of lactation since zeolite was added into feeding a month before calving.

Over days in milk of a milk fat the cows of the test group produced more by $10.26 \mathrm{~kg}$. The animals of the test group produced $256.34 \mathrm{~kg}$, or $10.82 \%$ more milk than the animals of the control group.

Similar data were also obtained by L.Ya. Makarenko [13] with the introduction of $230 \mathrm{~g}$ of zeolite into the diet of milk cows.

The milk productivity of cows over 305 days of lactation is shown in Figure 2.

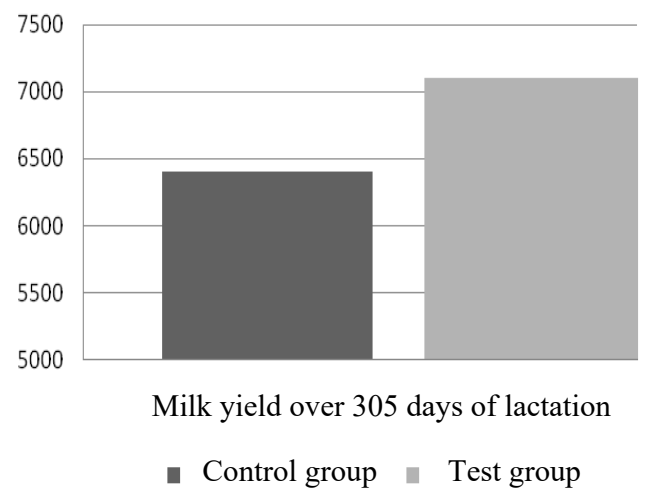

Fig. 2. Coefficients of nutrient digestibility, $\%$

The equations are an exception to the prescribed Over 305 days of lactation the cows of the test group produced $4 \%$-fat milk more by $692.81 \mathrm{~kg}$ or $10.82 \%$ than their analogs of the control group.

Feeding conditions of animals influence the composition and quality of milk (Table 2).

TABLE II. CHEMICAL COMPOSITION OF MILK $(\mathrm{X} \pm \mathrm{SX})($ ON AVERAGE OVER THE TEST)

\begin{tabular}{|c|c|c|}
\hline \multirow{2}{*}{ Indicator } & \multicolumn{2}{|c|}{ Group } \\
\cline { 2 - 3 } & control & test \\
\hline Nonfat milk solids, \% & $8.76 \pm 0.06$ & $8.65 \pm 0.09$ \\
\hline Density, ${ }^{\circ} \mathrm{T}$ & $30.21 \pm 0.07$ & $29.55 \pm 0.19$ \\
\hline Fat mass fraction, \% $^{*}$ & $3.98 \pm 0.22$ & $4.05 \pm 0.10$ \\
\hline Protein mass fraction, \% & $3.18 \pm 0.04$ & $3.17 \pm 0.01$ \\
\hline Calcium, g/kg $/ \mathrm{kg}$ & $1.60 \pm 0.01$ & $1.17 \pm 0.05$ \\
\hline Phosphorus, g/kg & $1.15 \pm 0.04$ & \\
\hline
\end{tabular}

The feeding of zeolite influenced the mineral composition of milk. Calcium and phosphorus content in milk of the animals of the test group is higher by $2.50(\mathrm{P}<0.05)$ and $1.74 \%$ respectively than of the control group, on. 
The main criterion to assess the natural feed additives is their environmental safety. Heavy metals are considered the main pollutants since their technological accumulation in the environment is particularly high. They are able to suppress the most significant metabolic processes, slow down the growth and development of animals thus reducing productivity and deteriorating the quality of production. The main danger of heavy metals to animal organism is their continuous accumulation. The introduction of natural agents having high adsorptive and ion-exchange properties to a diet accelerates the transition of toxins to excretion [14].

The study of milk regarding the content of heavy metals showed that the content of lead, arsenic and cadmium in all milk samples was below the allowable level.

Natural zeolites can absorb radioisotopes, remove heavy metals from an organism, reduce digestive disorder, ensure better use of nitrogenous and other nutrients of feed diets, increase activity and stability of digestive tract enzymes and eventually improve productivity at cost reduction per unit of production.

The obtained results make it possible to conclude that zeolite feeding does not deteriorate the quality of milk and does not exert negative impact on its biological value.

The use of zeolite in diets of cows is positive in terms of reproduction indicators. All animals safely brought forth calves, labor cuts and retention of afterbirth were not recorded. The cows were tupping in due time and successfully put in calves.

Thus, the service period in the test group was 15 days shorter $(\mathrm{P}<0.05)$, the conception rate was $16.70 \%$ less $(\mathrm{P}<0.05)$. The cows of the test group recovered much quicker and were quicker impregnated over 100 days of lactation after calving and were characterized by higher milk productivity.

The morphological and biochemical composition of blood is quite stable at proper and complete feeding of animals with nutrients. Insufficient or, on the contrary, excessive feed compounds deteriorate the metabolic processes in tissues thus affecting the blood composition.

Therefore, the study of hematologic indicators helps to understand and bound these changes to productivity.

The morphological blood parameters of animals were at the level of physiologically normal state. The hemoglobin content, red blood and white blood count were in all groups were almost at the same level and had no significant differences.

Mineral substances are important for the activity of cow organism, and their content in blood serum depends, first of all, on feeding and physiological condition of an organism.

The content of calcium and phosphorus in blood serum of cows was at the level of physiologically normal state.

Carotene is a precursor of vitamin A. Its content in blood serum is a reliable criterion of animal vitamin availability. The standard carotene content in the blood serum of cattle ranges within $0.3-0.6 \mathrm{mg} \%$. Despite the fact that the experiments were carried out in winter and spring, the concentration of carotene in the blood of animals was at the level of physiologically normal state, which indicates its availability in diets.

Therefore, the feeding of zeolite to animals did not cause any negative effect on blood composition and physiological condition of experimental animals.

With the increase of total costs for milk production from the cows of the test group caused by zeolite cost the sale of milk in the test group made 2032.77 rub (10.82\%) higher than in the control group. As a result, the profitability of milk production in the test group is 1.96 higher.

Thus, the introduction of zeolite into the diet of cows during the DIM period positively influenced the milk productivity, cost and profitability of milk production. During the DIM period the cows fed with $200 \mathrm{~g}$ of zeolite per head a day produced more $4 \%$-fat milk by $256.34 \mathrm{~kg}$ or $10.82 \%$ than the animals of the control group, and over 305 days of lactation - by $692.81 \mathrm{~kg}$.

\section{USE OF COMPOUND FEED WITH BENTONITE IN COW DIETS}

The diet of milk cows fully satisfied the maintenance and production requirements.

The digestibility coefficients serve as important indicators of feed nutrients consumed by animals. Thus, the digestibility coefficients of macronutrients consumed by animals of the test group were significantly higher compared to cows of the control group: dry matter - by $1.68 \%$; organic substances - by 1.52; crude fat - by 1.52 ; crude fiber - by $6.48 \%(\mathrm{P}<0.05)$.

T.N. Kokov, A. Utizhayev, et al. [15] observed the increase of digestibility coefficients and use of diet nutrients concerning all organic substances, when milk cows were fed with silo rich in bentonite clay.

According to A.P. Dmitrochenko, E.M. Moroz [16], the multicomponent mineral composition of bentonite clays improves intestinal peristalsis thus preventing too fast movement of content along the digestive tract and ensuring better digestion and absorption of nutrients. This improves the use of nutrients and increases the productivity.

The increase of protein content in a diet is not always accompanied by the increase of nitrogen balance since it depends on numerous factors, namely on the influence of microelements and vitamins on internal protein exchange.

The balance of nitrogen, calcium and phosphorus was calculated on the basis of physiological data.

All animals had a positive nitrogen balance during the physiological experiment.

The maximum release of nitrogen with milk was noted in cows of the test group $-125.88 \mathrm{~g}$, which is $18.49 \%(\mathrm{P}<0.05)$ higher than in cows of the control group.

The cows of the test group more efficiently used nitrogen for production from accepted and digested - by 6.69 and $8.92 \%$ compared to animals of the control group. 
Mineral nutrition is critical to define the feeding adequacy of farm animals. To assess the availability of animals with mineral substances not only the gross content in feed but also the extent of digestion by an organism matters.

The animals of all groups had positive balance of calcium and phosphorus, which demonstrates adequate availability of cows with these macroelements.

The highest calcium content was removed with milk of animals of the test group, which is by $7.36 \%(\mathrm{P}<0.05)$ higher than of the control group.

The situation with phosphorus utilized by animals is similar to calcium.

The main objective of trying to obtain a higher milk yield is the maximum milk production in the first 100 days of lactation.

As a result, it was established that over the studied period the highest milk yield was received from cows of the test group. Thus, during the experiment it was received significantly $(\mathrm{P}<0.05)$ more naturally fat milk from cows of the test group by $251.67 \mathrm{~kg}(9.62 \%)$ in comparison with animals of the control group.

V. Raitskaya, M. Nikitina, A. Utizhayev, A.P. Bulatov, et al. observed the increase of average daily milk yield when the cows were fed with bentonite clay, silo enriched with bentonite and premix on the basis of bentonite [6].

The protein content in the milk of the test animals has no significant differences but on kilogram basis of milk protein there was a significant $(\mathrm{P}<0.05)$ difference in favor of animals of the test group. This group produced more milk protein - by $8.46 \mathrm{~kg}(11.37 \%)$ in comparison with the control group.

The production of milk fat from cows of the test group over the experiment made $106.95 \mathrm{~kg}$, which is by $10.12 \%$ higher than that of the control group.

Over 305 days of lactation the cows of the control group produced $6474.61 \mathrm{~kg}$ of $4 \%$-fat milk, and the cows of the test group fed with bentonite $-7130.24 \mathrm{~kg}$, which is $655.63 \mathrm{~kg}$ more. The production of milk fat and protein over the period of lactation of the test group was $10.11 \%$ and $11.35 \%$ more respectively.

The study of physical and chemical indicators of milk indicated the increased content of nonfat milk solids in milk of cows of the test group in relation to the control group. The increase of nonfat milk solids is caused by the increase of milk protein content of cows of the test group. The introduction of bentonite into the diet of cows of the test group increased calcium contents in milk by $9.93 \%$ in comparison with the control group.

The study showed that bentonite has no negative impact on the biological value of milk, the concentration of heavy metals was lower the allowable level.

Thus, the advantage of animals of the test group regarding milk productivity values confirms the efficiency of bentonite as mineral feeding for milk cows.
The morphological and biochemical composition of blood is quite stable at proper and complete feeding of animals with nutrients.

TABLE III. PHYSICAL AND CHEMICAL COMPOSITION OF MILK $(\mathrm{X} \pm \mathrm{SX})$

\begin{tabular}{|c|c|c|}
\hline \multirow{2}{*}{ Indicator } & \multicolumn{2}{|c|}{ Group } \\
\cline { 2 - 3 } & control & test \\
\hline Content, \%: & & $4.09 \pm 0.83$ \\
\hline Fat mass fraction & $4.11 \pm 0.93$ & $3.17 \pm 0.01$ \\
\hline Protein mass fraction & $3.15 \pm 0.02$ & $8.87 \pm 0.07$ \\
\hline Nonfat milk solids & $8.79 \pm 0.17$ & $1.55 \pm 0.03^{*}$ \\
\hline Calcium, g & $1.41 \pm 0.04$ & $0.91 \pm 0.06$ \\
\hline Phosphorus, g & $0.80 \pm 0.02$ & $28.90 \pm 0.24$ \\
\hline${\text { Density, } \mathrm{A}^{\mathrm{o}}}$ & $30.10 \pm 0.22$ & \\
\hline
\end{tabular}

Insufficient or excessive feed compounds deteriorate the metabolic processes in tissues thus affecting the blood composition.

The biochemical blood test was carried out to characterize the physiological condition of animals.

The morphological and biochemical blood indicators of the test animals were at the level of physiologically normal state.

The cows of the test group are characterized by the tendency towards the increase of alkaline reserve by $3.09 \%$, sugar - by $30.41(\mathrm{P}<0.05)$, calcium - by $1.82 \%$ in comparison with similar blood indicators of animals of the control group.

The alkaline reserve was higher in animals receiving bentonite, they were also characterized by higher calcium level in blood. These data demonstrate that cows of the test group better acquired mineral substances. The calcium balance of animals of the test group was higher in comparison with the control group.

Blood protein is a necessary component of an organism, which performs an active function in all physiological and biochemical processes.

The level of total protein corresponded to physiological standard, which demonstrates sufficient protein availability of cows. The animals of the test group had the maximum level of total protein $-8.72 \mathrm{~g} \%$. High level of total protein in blood serum is typical for highly productive animals. The milk yield of animals of the test group was higher than that of the control group.

The blood sugar level indicates the condition of carbohydrate metabolism. The sugar content in cows of the control group was below standard and made $36.50 \mathrm{mg} \%$, while the animals of the test group had higher sugar level $47.60 \mathrm{mg} \%$, which is by $30.41 \%(\mathrm{P}<0.05)$ higher than that of the control group. Feed enrichment with bentonite contributed to normalization of blood biochemical composition of experimental animals. 


\section{CONCLUSION}

It is found that bentonite improves metabolism, ensures better digestion of nutrients, increases productivity by $5-8 \%$, natural resistance and contributes to high quality production.

The study makes it possible to conclude that it is advisable to introduce bentonite into a diet of milk cows during the DIM period in the amount of $200 \mathrm{~g}$ per head a day.

Thus, the use of local sources of cheap natural mineral resources (zeolite and bentonite) allows obtaining environmentally safe and complete livestock products at the least possible cost.

\section{References}

[1] K.Ya. Motovilov, V.V. Aksenov, V.A. Volkov, "Prospects of using carbohydrate feed additive from grain starch crops in livestock farming", In Proceedings of the III international scientific and preactical conference, Mocow: Dubrovtsa, 2005, pp. 45-46 [Modern technological and breeding aspects of livestock farming in Russia, 2005]

[2] N.A. Lushnikov, O.N. Grekhova, "Use of Zyryanka bentonites as premix fillers for pigs", In Proc. of Int. Conf. for Anniverary of Kurgan State Agricultural Academy named after T.S. Maltsev, Kurgan, 2003, pp. 110-120 [Rational use of feed supplies of the Trans-Ural region, 2003

[3] A.P. Bulatov et al, "Use of bentonite in livestock and poultry farming", Kurgan: Trans-Ural region, 2005, p. 206

[4] I.V. Petrukhin, "Feed and feed additives. Reference book", Moscow: Agropromizdat, 1989, pp. 200-474.
[5] G.I. Kalachnyuk, Yu.N. Lytsur, "Biotechnological fundamentals of efficient feed combinations with sorbents", In Proceedings of the $3^{\text {rd }}$ BIFIB international conference on farm animals, Borovsk, 2000, pp. 94 95 [Current problems of biology in livestock farming, 2000].

[6] V. Raitskaya, M. Nikitina, T. Kuznetsova, "Bentonites - highly effective additives", Livestock farming in Russia. 2005, No. 6, p. 55.

[7] M.A. Verotchenko et al, "Use of hitozin and zeolite as sorbents of heavy metals", Zootechnics, 2005, No. 7, pp. 30-32.

[8] A.I. Ashanin, N.A. Zhalyzbekov, "Zootechnical and economic efficiency of silo prepared with the use of zeolite", Siberian Herald, 2006, No. 3, pp. 58-62.

[9] S.P. Babich, O.A. Gorbatenko, O.V. Gorelik, "Dairy efficiency of cows when using natural zeolites", In Proceedings of the international scientific and preactical conference, Barrow: Zauralie, Vol. 2, 2004, pp. 99-100 [Scientific results - to Agro-industrial production, 2004].

[10] V.S. Zoteev, V.N. Vinogradov, M.P. Kirilov, S.V. Kumarin, "Metabolism and efficiency of cows when using compound feeds with zeolite tuff', Zootechnics, 2006, No. 4, pp. 8-12.

[11] M.K. Gaynulina, "Cheap additives and high profit", Livestock farming in Russia, 2004, No. 4, pp. 16-17.

[12] G.A. Romanov, "Zeolites: Efficiency and application in agriculture", Moscow: Rossinformagroteks, 2000, pp. 13-22.

[13] L.Ya. Makarenko, "Efficiency of zeolites of the Pegassky field in cattle feeding", extended abstract of Dr. Sci. (Agricultural Sciences) Dissertation, Novosibirsk, 2003, p. 48.

[14] V.E. Ulitko, L.N. Lukichev, A.L. Ignatov, "Efficiency of zeolitecontaining rocks to decrease the heavy metals content in cow organisms", Zootechnics, 2007, No. 11, p. 14.

[15] A. Utizhayev, T. Kokov, A. Kazharov, "Influence of bentonite clay in silage on mineral content of cow feed", Dairy and meat cattle breeding 2007, No. 4, pp. 15-16.

[16] A.P. Dmitrochenko, Z.M. Moroz, "Use of natural bentonites enriched with fat in diets of animals and birds", Herald of agricultural science, 1972, No. 9, pp. 12-18. 